\title{
25 Research Soure \\ Electrolyte and Acid-base Disturbances in Emergency High-risk Abdominal Surgery, A Retrospective Study
}

Mirjana Cihoric ( $\square$ mirjana.cihoric.03@regionh.dk)

Hvidovre Hospital https://orcid.org/0000-0001-8970-639X

Henrik Kehlet

Rigshospitalet

Morten Laksafoss Lauritsen

Hvidovre Hospital

Jakob Højlund

Hvidovre Hospital

Nicolai Bang Foss

Hvidovre Hospital

Research

Keywords: Emergency laparotomy, Electrolyte disturbances, Perioperative care, Resuscitation fluids

Posted Date: April 30th, 2021

DOI: https://doi.org/10.21203/rs.3.rs-468601/v1

License: () (1) This work is licensed under a Creative Commons Attribution 4.0 International License. Read Full License

Version of Record: A version of this preprint was published at World Journal of Surgery on March 9th, 2022. See the published version at https://doi.org/10.1007/s00268-022-06499-9. 


\section{Abstract}

\section{BACKGROUND}

Patients undergoing emergency high-risk abdominal surgery potentially suffer from both systemic dehydration and hypovolaemia. Data on the prevalence and clinical impact of electrolyte disturbances in this patient group, specifically the potential differences in patients with intestinal obstruction (IO) versus perforated viscus (PV) is lacking.

\section{METHODS}

In this retrospective single center cohort study, adult patients undergoing emergency high-risk abdominal surgery in a standardized perioperative pathway were included. Electrolyte and arterial blood gas analysis were measured prior to and just after surgery. Prevalence and clinical impact of electrolyte disturbances were assessed.

\section{RESULTS}

A total of 354 patients were included in the study. Acid-base and electrolyte disturbances had a high incidence in both groups with preoperative alkalemia dominating preoperatively, significantly more prevalent in 10 (45 vs.32\%, $\mathrm{p}<.001)$, and acidosis being most pronounced postoperatively in PV (49 vs. $28 \%, \mathrm{p}<.0001)$. Preoperative hypochloraemia and hypokalemia were more prevalent in the 10 group (34 vs $20 \%$ and 37 vs $25 \%$ respectively). Hyponatremia was highly prevalent in both $\mathrm{IO}$ and $\mathrm{PV}$.

Of the electrolyte and acid-base disturbances pre-and postoperative hypochloremia were the only ones independently associated with day-30 postoperative major complications and/or death in patients with IO, OR $2.87(1.35,6.23) p=0.006$ and OR $6.86(1.71,32.2) p=0.009$ respectively.

Hypochloremic patients presented with reduced long-term survival as compared with the normo- and hyperchloremic patients, with postoperative hypochloremia having the most pronounced association $(p<0.05)$. Neither plasma sodium nor potassium showed association with outcome.

\section{CONCLUSION}

These observations suggest that both acute high risk abdominal patient have frequent preoperative alkalosis shifting to postoperative acidosis, and that both pre- and postoperative hypochloremia are independently associated with both impaired short- and long-term outcome in patients with intestinal obstruction, which potential implications for the choice of resuscitations fluids. Research on pathophysiology and treatment strategies for electrolyte disturbances are needed in patients undergoing emergency high-risk abdominal surgery.

\section{Background}

Intravenous fluid therapy is one of the most frequent interventions in critically ill patients(1). All high-risk surgical patients are given intravenous fluid therapy(2) and abnormalities in acid-based homeostasis and electrolytes are common but insufficiently described.

Patients undergoing emergency high-risk abdominal surgery due to e.g. intestinal obstruction (IO) or perforated viscus (PV) potentially suffer from systemic dehydration due to inadequate fluid intake, vomiting ,pathological 
vasodilation with subsequent hypotension and preload dependency as well as increased capillary permeability, but also hypovolemia due to blood loss and overwhelmingly sepsis $(3,4)$.

Acute intestinal gut dysfunction resulting in malabsorption of macronutrients and/or water and electrolytes is almost universal in these patients, leading to a requirement for intravenous fluid and electrolyte supplementation(5). This condition is accompanied by both septic and metabolic complications as well as electrolyte shifts.

Further possible mechanisms for electrolyte disturbances include reduced kidney perfusion due to hypovolemia or hypotension; activation of hormonal systems such as renin-angiotensin-aldosterone system and vasopressin; and tubular dysfunction caused by ischemic or nephrotoxic kidney damage(6).

Sodium and chloride are the main ions of solutions used for volume expansion in critically ill and surgical patients. Due to the administration of large volumes of normal saline and/or a decreased urinary output, iatrogenic electrolyte disorders such as hyperchloremic acidosis or dysnatremia are common abnormalities in the clinical practice(7) and appear to be associated with worse outcome(8-10). This has led to a shift towards hypochloraemic fluids( balanced solutions ) in perioperative care, but the impact of these on outcome is controversial, and their optimal use in the care of emergency abdominal surgery has not been established.

As such, detailed descriptive data on the prevalence and clinical impact of electrolyte disturbances in patients undergoing emergency high-risk abdominal surgery is lacking(11). This study aimed to assess the prevalence of electrolyte and acid-base disturbances and the associations with postoperative outcome in patients undergoing emergency high-risk abdominal surgery, treated within a standardized pathway, specifically focusing on potential differences in patients with 10 versus PV.

\section{Methods}

\section{Design, settings, patients}

This was a planned sub-study of the principal trial(12) approved by the Danish Data Protection Agency (HVH2013-014/052), though not addressed in the original study. In consensus with Danish law, The Regional Committee on Health Research Ethics waived the requirement for informed patient consent (H-19011165). The manuscript followed the Strengthening The Reporting of Observational Studies in Epidemiology (STROBE) statement.

Primary outcome was incidence of electrolyte disturbances in patients undergoing emergency high-risk abdominal surgery. Secondary outcomes were postoperative 30-day mortality and postoperative complications, as well as ICU stay. Exposure variables included but were not limited to age , ASA, functional performance, cardiac, pulmonary and renal comorbidities, serum electrolyte levels.

Data was be obtained from the electronic patient record (EPR) and documented using a standard report formula. There was a $100 \%$ follow-up on mortality through the Danish Civil Registration System. We evaluated patients undergoing emergency surgery due to suspicion of abdominal pathology from 1 June 2013 to 21 February 2015 (figure 1). The identification of these patients was done through electronic medical records. 
Adults (18 years or over) undergoing emergency high-risk abdominal surgery for following abdominal pathology were included in the study: perforated viscus, intestinal obstruction, emergency re-operation after elective surgery, including anastomotic leak, postoperative perforated viscus owing to other than anastomotic leak and postoperative obstruction. Patients operated due to primary intestinal ischemia, primary abdominal bleeding, traumas, gynecological, urogenital and other vascular pathology, pregnant patients, reoperation owing to fascial separation with no other abdominal pathology identified and sub-acute colorectal cancer-surgery were excluded from the cohort. Appendectomies, cholecystectomies, negative diagnostic laparoscopies /laparotomies, herniotomies without bowel resections, sub-acute internal hernias after gastric bypass surgery, acute internal hernias without ileus, sub-acute surgery for inflammatory bowel diseases were excluded as well. Patients with missing data on fluid administration, vasopressor and inotropes administration, plasma electrolyte levels; as well as patients transferred to another hospital immediately following surgery were also excluded.

\section{Perioperative management}

At this surgical center, a multimodal standardized protocol(12) was applied to patients undergoing emergency high-risk abdominal surgery with focus on fast track surgery, with a senior surgeon and a senior anesthesiologist in charge of triage and preoperative treatment including preoperative resuscitation and optimization. Preoperative high dose broad-spectrum prophylactic antibiotics, on-demand abdominal CT within $2 \mathrm{~h}$, surgery within $6 \mathrm{~h}$ after the decision to operate, peri-operative stroke volume(SV) guided fluid resuscitation (goal directed therapy (GDT)- via LiDCO Rapid guided fluid management (patients optimized by GDT had an arterial catheter placed through the radial or brachial artery) (LiDCOrapidTM; LiDCO, London, UK)(13-15), thoracic epidural analgesia when not contraindicated, Post-operative High Dependency Unit (PACU) stay for high risk patients, and early physiotherapy and mobilization.

Perioperative stroke volume guided fluid- and hemodynamic-management was applied through a standardized protocol for anesthesia and followed present NELA recommendations(3) during surgery and for first 24 hours after surgery.

Patients received a rapid sequence induction and intubation with Remifentanil, Propofol and muscle relaxant. General anesthesia was maintained with Remifentanil and Propofol, while subsequent intraoperative treatment was left to the discretion of the attending anesthesiologist guided by the institutional protocol.

The electronic medical records of enrolled patients were reviewed, and pre-, intra-, and postoperative data were collected, including demographics; comorbidities; intraoperative hemodynamics and hemodynamic therapy; surgery characteristics; pre- and postoperative blood analysis, postoperative defined as drawn up to two hours after end of surgery. Fluid administration and sensible fluid losses (output: urine, fecal, aspirate, drainage) were registered (crystalloids, colloids, blood products separately) through intraoperative anesthesia charts and postoperative PACU charts, calculated in milliliters.

\section{Fluid administration}

The preoperative resuscitation fluid amount constitutes a part of the intraoperative fluid balance and fluid administration. Intraoperative fluid balance and fluid balance for up to 24 hours postoperatively was calculated as the total fluid input (volume of colloids, crystalloids, transfusions) minus fluid output (urine output, fluid from 
drains and gastric aspiration). Intra- and postoperative fluid balances were calculated in 6- hour intervals, maximal for 24 hours after surgery.

\section{Chloride rich vs. chloride restrictive fluids}

In this study, chloride rich (hyperchloremic) fluids included $0.9 \%$ saline (chloride concentration, $154 \mathrm{mmol} / \mathrm{I}), 4 \%$ succinylated gelatin solution (chloride concentration, $154 \mathrm{mmol} / \mathrm{l}$ ). Chloride restrictive (hypo/normochloremic) fluids included Ringer's acetate crystalloid solutions (chloride concentration, $110 \mathrm{mmol} / \mathrm{l}$ ), a balanced buffered solution (chloride concentration, $45 \mathrm{mmol} / \mathrm{I}$ ), and a $20 \%$ albumin solution (chloride concentration, $19 \mathrm{mmol} / \mathrm{I}$ ).

\section{Selection of plasma sodium, potassium and chloride cut-offs}

Patients were divided into groups based on admission plasma sodium, potassium and chloride concentrations for the purpose of analysis. The normal range for plasma sodium, potassium and chloride in our laboratory is 137-144 $\mathrm{mmol} / \mathrm{I}$ and 3,5-4,4 $\mathrm{mmol} / \mathrm{I}$ and $98-106 \mathrm{mmol} / \mathrm{I}$ respectively and were chosen as the initial cut-off points. The normal reference range represents the "rounded of" 95\% confidence interval of sodium, potassium and chloride values for a standardized group of normal subjects selected from the local population.

All patients with admission plasma sodium value of $145 \mathrm{mmol} / \mathrm{l}$ or higher were classified as having hypernatremia and those with an initial plasma sodium within the normal range were included in the control group. Hyponatremia is generally defined as a sodium concentration of less than $135 \mathrm{mmol} / \mathrm{L}$, with severe hyponatremia being below $120 \mathrm{mmol} / \mathrm{l} 14$, cut-off values of 130 and $120 \mathrm{mmol} / \mathrm{I}$ were chosen to divide the hyponatremic patients into mild, moderate and severe categories.

All patients with admission plasma potassium value over $4,6 \mathrm{mmol} / \mathrm{l}$ were classified as having hyperkalemia and those with initial plasma potassium within the normal range were included in the control group. Levels below 3.5 $\mathrm{mmol} / \mathrm{L}$ defined as hypokalemia and defined severe when levels are less than $2.5 \mathrm{mmol} / \mathrm{L}(16)$.

All patients with admission plasma chloride value less than $98 \mathrm{mmol} / \mathrm{l}$ were considered hypochloremic, while hyperchloremia was defined as plasma chloride value above $106 \mathrm{mmol} / \mathrm{l}$.

\section{Statistics}

Statistical analysis was performed using R Statistical Software. Patients were classified into hypo- normo- and hyper-condition as previously described, based on their baseline levels.

Continuous variables were presented as means \pm standard deviation or median (interquartile range), categorical variables as numbers and \%ages. T-test was applied in comparison of normally distributed data, and Wilcoxon signed-rank for non-normally distributed data. For categorical variables, a chi-square test was used.

Logistic regression was used to test for association of chloride, potassium and sodium parameters with postoperative outcome.

Univariate logistic regression was used to test for unadjusted association between chloride/sodium/potassium and outcome. Multivariate logistic regression was used to test for association between chloride/sodium/potassium and outcome after adjusting for potential confounders. Independent variables from univariate models were incorporated as covariates in the multivariate regression model. 


\section{Results}

During the inclusion period, 600 patients underwent surgery for emergency high risk abdominal condition. Threehundred and fifty-four (354) patients were included in the analysis, 192 patients with intestinal obstruction(IO) and 162 patients with perforated viscus (PV) (figure 1).

Patient demographics are presented in table 1.

\section{Comparison of electrolyte levels and acid base status in patients with intestinal obstruction and perforated viscus}

Patients with PV were significantly more acidotic both prior to and after the surgery $(p<.0001)$, while patients with 10 presented with more prevalent alkalemia compared to $P V(p=0.0007)$ but normalizing postoperatively . Furthermore, there was an increase in proportion of acidemia in both cohorts pre- to postoperatively, most pronounced in patients with PV (figure 2).

Patients with 10 had higher incidence of hypochloraemia and hypokalemia preoperatively, whereas higher proportion of patients with PV presented with preoperative hyponatremia (figure 1). In total, preoperative hypochloremia was observed in 99 patients $(28 \%)$ of the cohort, while 88 patients $(25 \%)$ were hyperchloremic. Preoperative hypochloremia was significantly more frequent in those with $10(p=0.002)$. Preoperative hyponatremia was prevalent in $57 \%$ of the overall cohort, with $52 \%$ in the OI, and $64 \%$ of those with PV $(p=0.016)$. Significantly higher number of hypokalemic patients was also seen in the intestinal obstruction cohort, both prior and after surgery $(p=0.013$ and $p=0.002$ respectively).

\section{Impact of electrolyte levels and acid-base status on outcome}

Both cohorts had similar outcomes regarding day-30 adverse events incl. death (41.1 vs $51.2 \% ; p=0.050)$, Acute Kidney Injury (AKI) (15.1 vs $15.4 \%$; $p=0.932$ ) and need for Renal Replacement Therapy (RRT) (6.3 vs $11.7 \%$; $\mathrm{p}=0.668)$ (table 1).

Adjusted for age, gender, ASA, physical performance, co-morbid disease, sepsis and fluids administered, pre- as well as postoperative hypochloremia was significantly associated with day-30 postoperative major complications, including death in patients with IO, OR $2.87(1.35,6.23) p=0.006$ and OR $6.86(1.71,32.2) p=$ 0.009 respectively (appendix 1 ). This was not seen in patients with PV. Neither plasma sodium nor potassium changes were associated with 30-day complications.

Furthermore, after adjusting for age, gender, ASA, physical performance, co-morbid disease, sepsis and fluids administered, preoperative hypochloremia was associated with postoperative major complications, specifically pulmonary complications (adjusted OR $1.2595 \% \mathrm{Cl}[1.05,2.60], \mathrm{p}=0.035$ ) in patients with IO. No association was found in patients with PV.

In both cohorts, preoperative hyperlactatemia was associated with an increased risk of postoperative major complications, including death within the first 30 days(intestinal obstruction: OR 4.39 [1.42, 15.3], $p=0.013$; perforated viscus: OR $2.44 ; 95 \% \mathrm{Cl}, 1.24,4.92, p=0.010$ ) (appendix 1).

Figure 3 illustrates Kaplan Meier survival curve for (A) preoperative and (B) postoperative chloride levels and day30 mortality for patients undergoing emergency abdominal surgery. Hypochloremic patients presented with 
reduced long-term survival as compared with the normo- and hyperchloremic patients, with postoperative hypochloremia having the most pronounced association.

\section{Chloride and interaction with fluid administration}

Patients with IO presenting with hypochloremia received significantly more hyperchloremic fluids during ( estimate $173 \mathrm{~mL}, 95 \% \mathrm{Cl}(50-296), \mathrm{p}=0.005)$ and after surgery (estimate $476 \mathrm{~mL}, 95 \% \mathrm{Cl}(151-801), \mathrm{p}=0.004)$, normochloremic fluids after surgery (estimate $698 \mathrm{~mL}, 95 \% \mathrm{Cl}(520-1526), p=0.048)$, as well as overall 24 hour

fluid administration ( estimate $1604 \mathrm{~mL}, 95 \% \mathrm{Cl}(402-2807), \mathrm{p}=0.009)$, when compared to patients with normo- and hyperchloremia (linear regression models).

\section{Discussion}

In this retrospective analysis of 354 patients undergoing emergency high-risk abdominal surgery, perioperative electrolyte derangement was frequent, with a high incidence of hyponatremia and hypochloremia. We found significant associations between preoperative as well as postoperative hypochloremia and both overall morbidity and short- and long-term morbidity in patients with intestinal obstruction, which was not found in patients with perforated viscus. Neither sodium nor potassium derangement had statistically significant impact on postoperative outcome.

Data from a recent prospective observational investigation demonstrate that temporary hyperchloremia may occur in $75 \%$ of ICU patients during the first 24 hours of ICU stay(17). However, despite a rather high prevalence in critically ill patients, few outcome-related data regarding systemic chloride levels exist.

The available data suggest that, increased disease severity may be associated with abnormal chloride levels, however, in various cohort studies discrepant results exist(17-20). Our findings seem to be coincide with several negative retrospective cohorts assessing the role of hyperchloremia in critically ill patients(21-24), where hyperchloremia was not associated with worse outcome.

Although chloride is one of the major electrolytes, it is not measured routinely in daily practice and optimal management of hypochloremia is inadequately understood in the critically ill surgical patient(25). Emerging evidence shows that low chloride levels affects outcome in heart failure patients, $(26,27)$. Furthermore, several studies have found hypochloremia associated with impaired outcome in critically ill patients(25,28).

In patients with IO, we found a higher degree of electrolyte imbalances than in those with PV, specifically hypokalemia and hypochloremia. Thus, almost $35 \%$ of patients with 10 presented with preoperative hypochloremia, compared to only $24 \%$ of the patients with PV $(p=0.002)$. The manifestations of 10 and its degree of severity generally depend on the site of obstruction(29), however, both obstructive but also paralytic ileus are associated with profound effects on body fluid balance. Accumulation of fluids and gases drives elevated intraluminal pressure and inflammation, microcirculatory dysfunction of the bowel wall and disruption of the mucosal barrier results leading to fluid sequestration into the intestinal wall lumen, potentially accounting for several liters of fluid and promoting hypovolemia and electrolyte derangement $(30,31)$. It could be argued that patients with PV all have a degree of IO, either an obstruction as the underlying cause of perforation or paralysis of the intestines as a result of inflammation and stress, partly explaining the preoperative electrolyte derangement in patients with PV. 
Metabolic alkalosis, as was seen to be prevalent in the preoperative phase in patients with IO, could be caused by both hypochloremia and hypokalemia, while plasma contraction could further aggravate hypochloremic metabolic alkalosis especially in patients who loose high quantities of chloride-rich fluids(32) both via inadequate renal $\mathrm{Cl}$ - reabsorption or via dilution following infusion of hypotonic fluids(33,34). Another cause of abnormality of chloride concentration might be the derangement of adrenal hormones triggered by surgical stress. As the current study is a retrospective observational study, the cause of hypochloremia was not ascertained. Future prospective studies focusing on the preoperative loss of chloride, as well as the postoperative adrenal function and inflammatory response, should be conducted to refute or confirm these considerations. In this context, a recently published retrospective study did find a statistically significant positive correlation between fluid balance and inflammation in patients with OI, as well as association between high pre- and postoperative C-reactive protein and a high positive fluid balance with worse outcome in patients with IO, but not in patients with $\mathrm{PV}(35)$.

Linear regression models found an association between preoperative hypochloremia and the amount of fluid administrated during the observational period in patients with IO. The severity of hypochloremia could be indicative of the severity of the 10 and the associated degree of dehydration and potential hypovolaemia, explaining the association between preoperative hypochloremia and postoperative major complications, specifically pulmonary complications. As such, the potential iatrogenic fluid overload as a result of treatment of hypovolemia with hypochloremic fluids could promote postoperative complications. Buffered intravenous fluids do indeed reduce the incidence of hyperchloremia and metabolic acidosis(36,37), however, the question remains if normal saline has a more advantageous position when treating patient with IO.

This is the first analysis describing electrolyte derangement and the potential role of hypochloremia on the outcome of patients undergoing emergency high-risk abdominal surgery. However, this is a retrospective cohort, thus prone to selection bias. The patients were classified into three groups hypo-, normo- and hyperchloremia according to our hospital laboratory reference; There are no clearly established cutoff values, hypochloremia is usually defined as serum chloride levels below $96-101 \mathrm{mmol} / \mathrm{l}$, while hyperchloremia normally is defined as serum chloride levels higher than 106-111 mmol/I(38). The definition varies depending on the local laboratory. Indeed, some studies showed an independent effect of hypochloremia defined as plasma chloride level below $100 \mathrm{mmol} / \mathrm{l}$, on cardiovascular, non-cardiovascular, and all-cause mortality(39-41). Also, we analyzed only change in chloride level pre-to immediate post operatively and data cannot be extrapolated beyond that.

We should note that this study is a hypothesis-generating study, indicating the need for future prospective research, which may assess the preoperative cause of hypochloremia and the mechanisms of its association with worse outcome. We also note that our results showed just the association of hypochloremia and higher mortality, but not the causality link.

\section{Conclusions}

Perioperative hypochloremia may have clinical importance as an indicator of prognosis in patients undergoing emergency high-risk abdominal surgery, with a significant association with morbidity in patients who have IO. Further studies should examine the pathophysiological similarities and more importantly differences in patients with $\mathrm{IO}$ and perforated viscus as well as potential effects of different resuscitation strategies for acute fluid and electrolyte disturbances emergency abdominal surgery. 


\section{Abbreviations}

IO Intestinal Obstruction

PV Perforated viscus

ICU Intensive Care Unit

PACU Post-anesthesia Care Unit

\section{Declarations}

Ethics approval and consent to participate

In consensus with Danish law, The Regional Committee on Health Research Ethics waived the requirement for informed patient consent.

Consent for publication

Not applicable.

Availability of data and materials

Original data is available from the corresponding author on reasonable request.

Competing interests

The authors declare that they have no competing interests.

Funding

This study was funded by Capital Region of Denmark.

Authors' contributions

MC, NBF, HK, JH and ML conceived and designed the study; MC, NBF and HK contributed in data management; MC, NBF, HK and JH collected and analyzed the data; MC, NBF, HK, JH and ML contributed in data analysis, interpretation of the data and drafting the manuscript. All authors read and approved the final manuscript.

Acknowledgements

Not applicable.

Authors' information (optional)

Corresponding author: Mirjana Cihoric, email: mirjana.cihoric.03@regionh.dk

\section{References}


1. Myburgh JA. Fluid resuscitation in acute medicine: What is the current situation? J Intern Med. 2015;277(1):58-68.

2. Finfer S, Liu B, Taylor C, Bellomo R, Billot L, Cook D, et al. Resuscitation fluid use in critically ill adults: an international cross-sectional study in 391 intensive care units. Crit Care [Internet]. 2010;14(5):R185.

3. Poulton T, Murray D, National Emergency Laparotomy Audit (NELA) project team. Pre-optimisation of patients undergoing emergency laparotomy: a review of best practice. Anaesthesia [Internet]. 2019 Jan;74 Suppl 1:100-7.

4. Tengberg LT, Cihoric M, Foss NB, Bay-Nielsen M, Gögenur I, Henriksen R, et al. Complications after emergency laparotomy beyond the immediate postoperative period - a retrospective, observational cohort study of 1139 patients. Anaesthesia. 2017;72(3):309-16.

5. Klek S, Forbes A, Gabe S, Holst M, Wanten G, Irtun $\varnothing$, et al. Management of acute intestinal failure: A position paper from the European Society for Clinical Nutrition and Metabolism (ESPEN) Special Interest Group. Clin Nutr [Internet]. 2016 Dec;35(6):1209-18.

6. Bagshaw SM, Townsend DR, McDermid RC. Disorders of sodium and water balance in hospitalized patients. Can J Anesth Can d'anesthésie [Internet]. 2009 Feb;56(2):151-67.

7. Lee JW. Fluid and Electrolyte Disturbances in Critically III Patients. Electrolytes Blood Press [Internet]. 2010;8(2):72

8. Sakr Y, Rother S, Ferreira AMP, Ewald C, Dünisch P, Riedemmann N, et al. Fluctuations in Serum Sodium Level Are Associated With an Increased Risk of Death in Surgical ICU Patients*. Crit Care Med [Internet]. 2013 Jan;41(1):133-42.

9. Vandergheynst F, Sakr Y, Felleiter P, Hering R, Groeneveld J, Vanhems P, et al. Incidence and prognosis of dysnatraemia in critically ill patients: analysis of a large prevalence study. Eur J Clin Invest [Internet]. 2013 Sep;43(9):933-48.

10. Stelfox HT, Ahmed SB, Zygun D, Khandwala F, Laupland K. Characterization of intensive care unit acquired hyponatremia and hypernatremia following cardiac surgery. Can J Anesth. 2010;

11. Grass F, Pache B, Butti F, Solà J, Hahnloser D, Demartines N, et al. Fluid management for critical patients undergoing urgent colectomy. J Eval Clin Pract [Internet]. 2019 Jun 17;26(1)(1):109-14.

12. Tengberg LT, Bay-Nielsen M, Bisgaard T, Cihoric M, Lauritsen ML, Foss NB, et al. Multidisciplinary perioperative protocol in patients undergoing acute high-risk abdominal surgery. Br J Surg. 2017;104(4).

13. Pearse RM, Harrison DA, MacDonald N, Gillies MA, Blunt M, Ackland G, et al. Effect of a Perioperative, Cardiac Output-Guided Hemodynamic Therapy Algorithm on Outcomes Following Major Gastrointestinal Surgery. Jama [Internet]. 2014;311(21):2181-90.

14. Grocott MPW, Dushianthan A, Hamilton MA, Mythen MG, Harrison D, Rowan K, et al. Perioperative increase in global blood flow to explicit defined goals and outcomes after surgery: a Cochrane Systematic Review. Br J Anaesth [Internet]. 2013 Oct;111(4):535-48.

15. Corcoran T, Emma Joy Rhodes J, Clarke S, Myles PS, Ho KM. Perioperative fluid management strategies in major surgery: A stratified meta-analysis. Anesth Analg. 2012;114(3):640-51.

16. Soar J, Perkins GD, Abbas G, Alfonzo A, Barelli A, Bierens JJLM, et al. European Resuscitation Council Guidelines for Resuscitation 2010 Section 8. Cardiac arrest in special circumstances: Electrolyte 
abnormalities, poisoning, drowning, accidental hypothermia, hyperthermia, asthma, anaphylaxis, cardiac surgery, trauma, pregna. Resuscitation [Internet]. 2010 0ct;81(10):1400-33.

17. Marttinen M, Wilkman E, Petäjä L, Suojaranta-Ylinen R, Pettilä V, Vaara ST. Association of plasma chloride values with acute kidney injury in the critically ill - a prospective observational study. Acta Anaesthesiol Scand [Internet]. 2016 Jul;60(6):790-9.

18. Neyra JA, Canepa-Escaro F, Li X, Manllo J, Adams-Huet B, Yee J, et al. Association of Hyperchloremia With Hospital Mortality in Critically III Septic Patients. Crit Care Med [Internet]. 2015 Sep;43(9):1938-44.

19. Suetrong B, Pisitsak C, Boyd JH, Russell JA, Walley KR. Hyperchloremia and moderate increase in serum chloride are associated with acute kidney injury in severe sepsis and septic shock patients. Crit Care [Internet]. 2016 Oct 6;20(1):315.

20. Shaw AD, Raghunathan K, Peyerl FW, Munson SH, Paluszkiewicz SM, Schermer CR. Association between intravenous chloride load during resuscitation and in-hospital mortality among patients with SIRS. Intensive Care Med [Internet]. 2014 Dec;40(12):1897-905.

21. Yessayan L, Neyra JA, Canepa-Escaro F, Vasquez-Rios G, Heung M, Yee J. Effect of hyperchloremia on acute kidney injury in critically ill septic patients: a retrospective cohort study. BMC Nephrol [Internet]. 2017 Dec 2;18(1):346.

22. Oh HJ, Kim SJ, Kim YC, Kim EJ, Jung IY, Oh DH, et al. An increased chloride level in hypochloremia is associated with decreased mortality in patients with severe sepsis or septic shock. Sci Rep [Internet]. 2017 Nov 21;7(1):15883.

23. Gunnerson KJ, Saul M, He S, Kellum JA. Lactate versus non-lactate metabolic acidosis: a retrospective outcome evaluation of critically ill patients. Crit Care [Internet]. 2006 Feb;10(1):R22.

24. Commereuc M, Nevoret C, Radermacher P, Katsahian S, Asfar P, Schortgen F, et al. Hyperchloremia is not associated with AKI or death in septic shock patients: results of a post hoc analysis of the "HYPER2S" trial. Ann Intensive Care [Internet]. 2019 Aug 22;9(1):95.

25. Kimura S, Matsumoto S, Muto N, Yamanoi T, Higashi T, Nakamura K, et al. Association of serum chloride concentration with outcomes in postoperative critically ill patients: A retrospective observational study. $\mathrm{J}$ Intensive Care. 2014;2(1).

26. Vaduganathan M, Pallais JC, Fenves AZ, Butler J, Gheorghiade M. Serum chloride in heart failure: a salty prognosis. Eur J Heart Fail [Internet]. 2016;18(6):669-71.

27. Prins KW, Kalra R, Rose L, Assad TR, Archer SL, Bajaj NS, et al. Hypochloremia Is a Noninvasive Predictor of Mortality in Pulmonary Arterial Hypertension. J Am Heart Assoc [Internet]. 2020;9(5):e015221.

28. Terzano C, Di Stefano F, Conti V, Di Nicola M, Paone G, Petroianni A, et al. Mixed acid-base disorders, hydroelectrolyte imbalance and lactate production in hypercapnic respiratory failure: the role of noninvasive ventilation. PLoS One [Internet]. 2012;7(4):e35245.

29. Markogiannakis H, Messaris E, Dardamanis D, Pararas N, Tzertzemelis D, Giannopoulos P, et al. Acute mechanical bowel obstruction: clinical presentation, etiology, management and outcome. World $\mathrm{J}$ Gastroenterol [Internet]. 2007 Jan 21;13(3):432-7.

30. Nellgård P, Jönsson A, Bojö L, Tarnow P, Cassuto J. Small-bowel obstruction and the effects of lidocaine, atropine and hexamethonium on inflammation and fluid losses. Acta Anaesthesiol Scand [Internet]. 1996 Mar;40(3):287-92. 
31. Nellgård P, Cassuto J. Inflammation as a Major Cause of Fluid Losses in Small-Bowel Obstruction. Scand J Gastroenterol [Internet]. 1993 Jan 8;28(12):1035-41.

32. Luke RG, Galla JH. It is chloride depletion alkalosis, not contraction alkalosis. J Am Soc Nephrol [Internet]. 2012 Feb;23(2):204-7.

33. Berend K, van Hulsteijn LH, Gans ROB. Chloride: the queen of electrolytes? Eur J Intern Med [Internet]. 2012 Apr;23(3):203-11.

34. Yunos NM, Bellomo R, Story D, Kellum J. Bench-to-bedside review: Chloride in critical illness. Crit Care [Internet]. 2010;14(4):226.

35. Cihoric M, Kehlet H, Lauritsen ML, Højlund J, Kanstrup K, Foss NB. Inflammatory response, fluid balance and outcome in emergency high-risk abdominal surgery. Acta Anaesthesiol Scand [Internet]. 2021 Feb 23;aas.13792.

36. Cieza JA, Hinostroza J, Huapaya JA, León CP. Sodium chloride $0.9 \%$ versus Lactated Ringer in the management of severely dehydrated patients with choleriform diarrhoea. J Infect Dev Ctries [Internet]. 2013 Jul 15;7(7):528-32.

37. Burdett E, Dushianthan A, Bennett-Guerrero E, Cro S, Gan TJ, Grocott MPW, et al. Perioperative buffered versus non-buffered fluid administration for surgery in adults. Cochrane database Syst Rev [Internet]. 2012 Dec 12;12:CD004089.

38. Pfortmueller CA, Uehlinger D, von Haehling S, Schefold JC. Serum chloride levels in critical illness-the hidden story. Intensive care Med Exp [Internet]. 2018 Apr 13;6(1):10.

39. Grodin JL, Simon J, Hachamovitch R, Wu Y, Jackson G, Halkar M, et al. Prognostic Role of Serum Chloride Levels in Acute Decompensated Heart Failure. J Am Coll Cardiol [Internet]. 2015 Aug 11;66(6):659-66.

40. Grodin JL, Verbrugge FH, Ellis SG, Mullens W, Testani JM, Tang WHW. Importance of Abnormal Chloride Homeostasis in Stable Chronic Heart Failure. Circ Heart Fail [Internet]. 2016 Jan;9(1):e002453.

41. De Bacquer D, De Backer G, De Buyzere $M$, Kornitzer $M$. Is low serum chloride level a risk factor for cardiovascular mortality? J Cardiovasc Risk [Internet]. 1998 Jun;5(3):177-84.

\section{Tables}

Table 1: Perioperative characteristics of 354 patients who underwent high-risk emergency abdominal surgery categorized by intraoperative pathology 


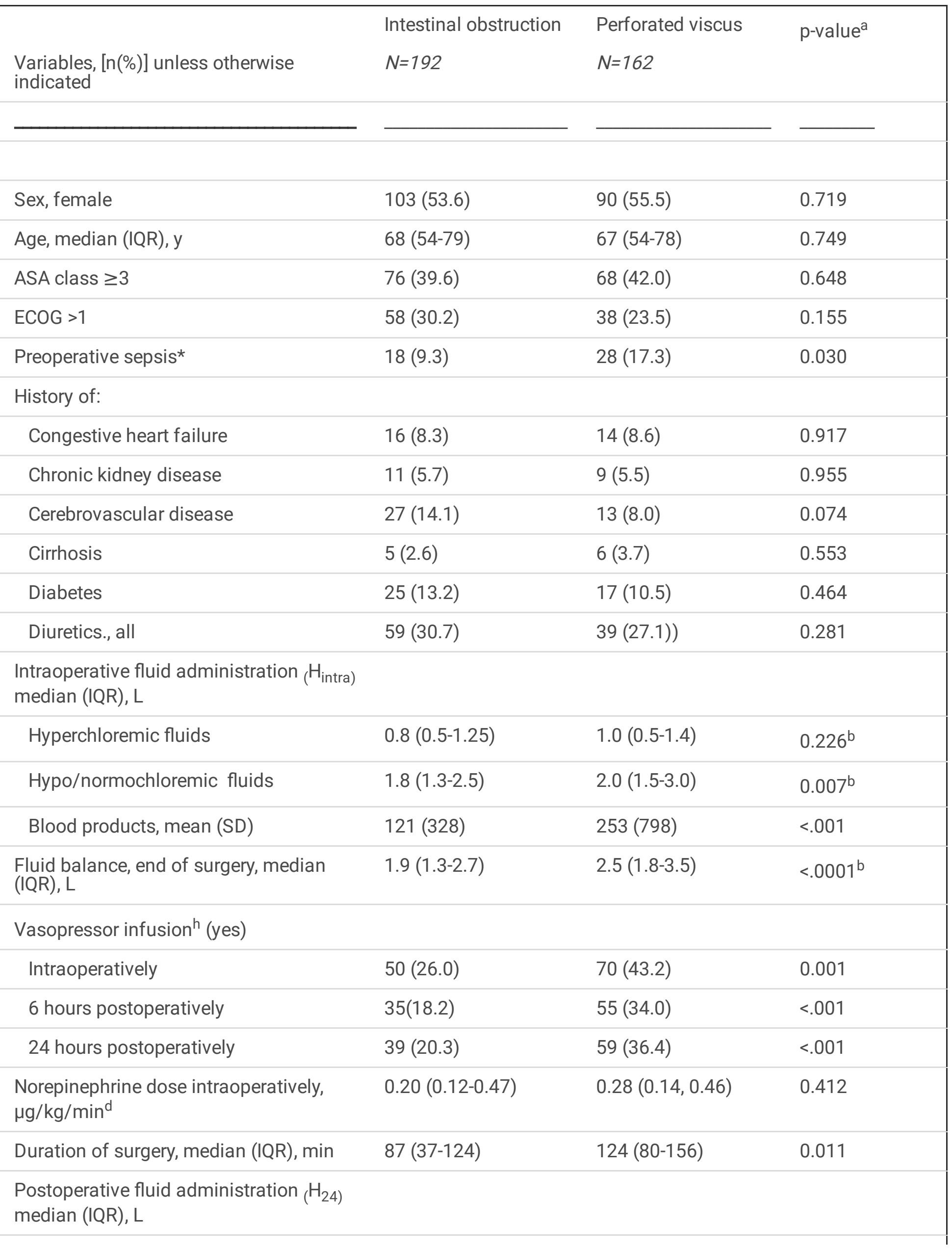




\begin{tabular}{|llll|}
\hline Hyperchloremic fluids & $1.8(0.6-3.1)$ & $2.0(1.0-3.7)$ & $0.120^{\mathrm{b}}$ \\
\hline Hypo/normochloremic fluids & $1.8(0.5-3.7)$ & $2.2(0.8-4.6)$ & $0.037^{\mathrm{b}}$ \\
\hline Blood products, mean (SD) & $110(548)$ & $372(2232)$ & $0.005^{\mathrm{b}}$ \\
\hline ICU stay No.(\%) & $34(17.7)$ & $46(28.4)$ & 0.017 \\
\hline Length of ICU stay, median, (IQR) & $1.5(0-0)$ & $3(0-1)$ & 0.016 \\
\hline Length of hospital stay, median, (IQR) & $9(5-16)$ & $13(6-26)$ & $<.0001$ \\
\hline Outcomes No. (\%) & & & 0.932 \\
\hline AKI & $29(15.1)$ & $25(15.4)$ & 0.668 \\
\hline Need for RRT & $12(6.3)$ & $19(11.7)$ & 0.050 \\
\hline $\begin{array}{l}\text { Day-30 postoperative major } \\
\text { complications incl death }{ }^{\mathrm{b}}\end{array}$ & $79(41.1)$ & $83(51.2)$ & 0.050 \\
\hline Day-30 mortality & $34(17.7)$ & $17(10.4)$ & \\
\hline
\end{tabular}

AKl; Acute kidney injury; RRT: renal replacement therapy; $\mathrm{H}_{\text {intra: }}$ time during surgery; Hyperchloremic fluids: Isotone Sodium chloride, Human Albumin 5\%, Voluven ${ }^{\circledR} ;$ Hypo/normochloremic fluids: Ringers acetate, Human albumin $20 \%$; a: chi square ; b: mann-whitney; h: Phenylephrine or Norepinephrine infusion; *severe sepsis, septic shock defined by 2016 Sepsis-3 guidelines

\section{Figures}




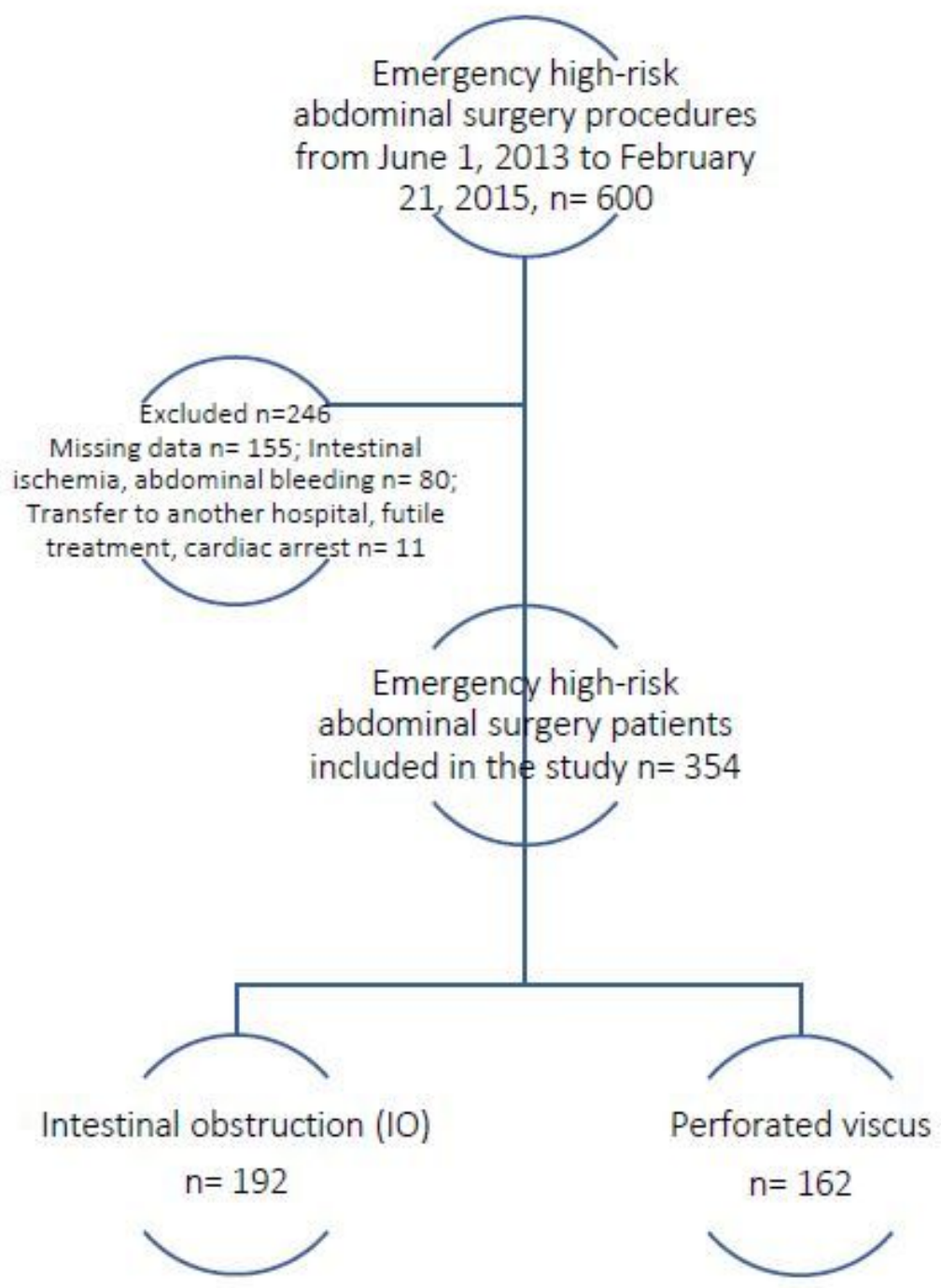

\section{Figure 1}

Flow diagram of patient selection during the study 

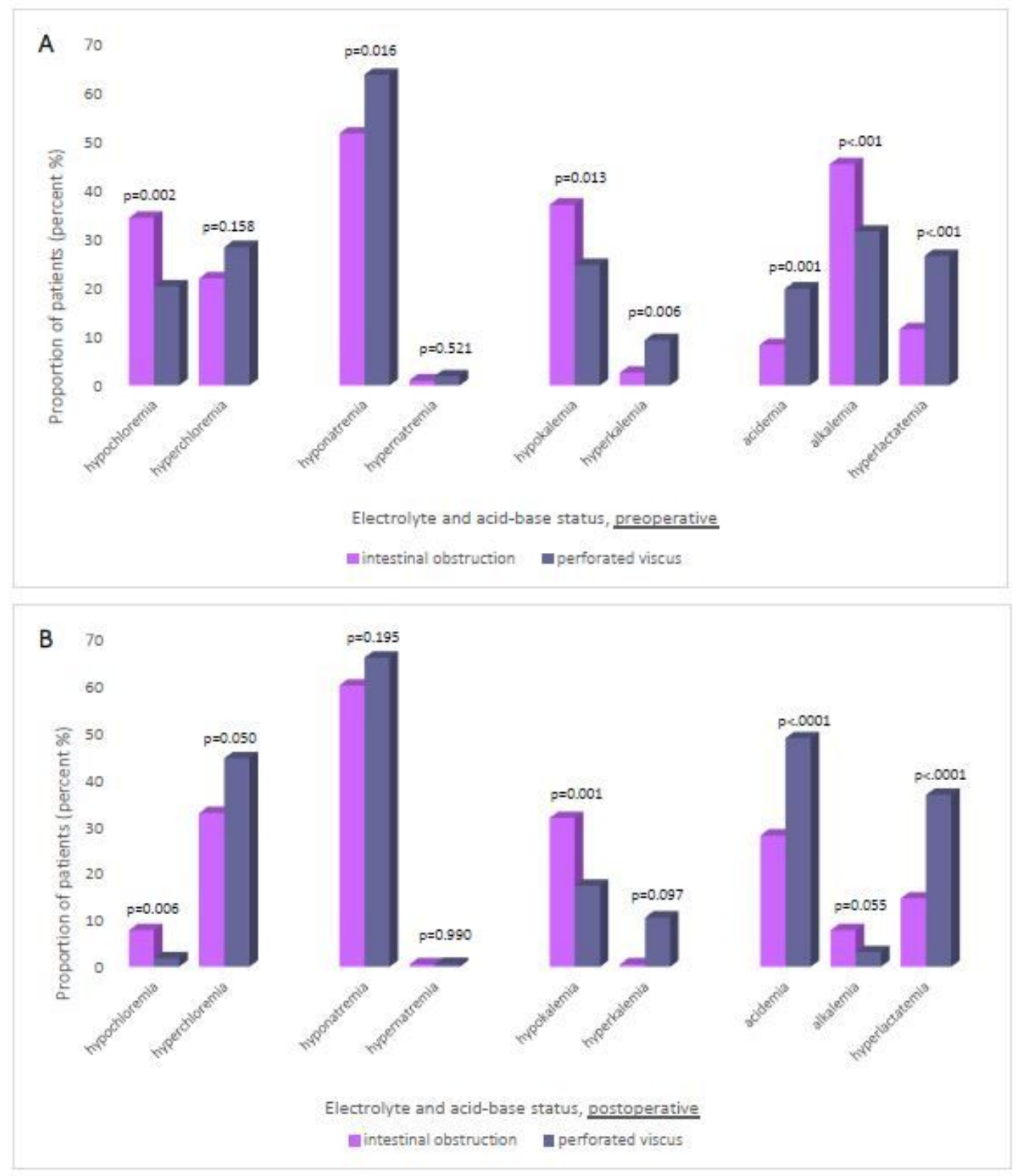

Figure 2

Electrolyte derangement, preoperative (A) and postoperative (B), for patients with intestinal obstruction and perforated viscus; Legend: Hypochloremia: <98 mmol/l; Hyperchloremia: >106 mmol/L; Hyponatremia: < 135 mmol/L ; Hypernatremia: >144 mmol/L ; Hypokalemia: <3.5 mmol/L ; Hyperkalemia: >4.5 mmol/L ; Acidemia: pH $<7.35$; f: Alkalemia: pH >7.45; g: Hyperlactatemia: lactate > 2.1 mmol/L; 


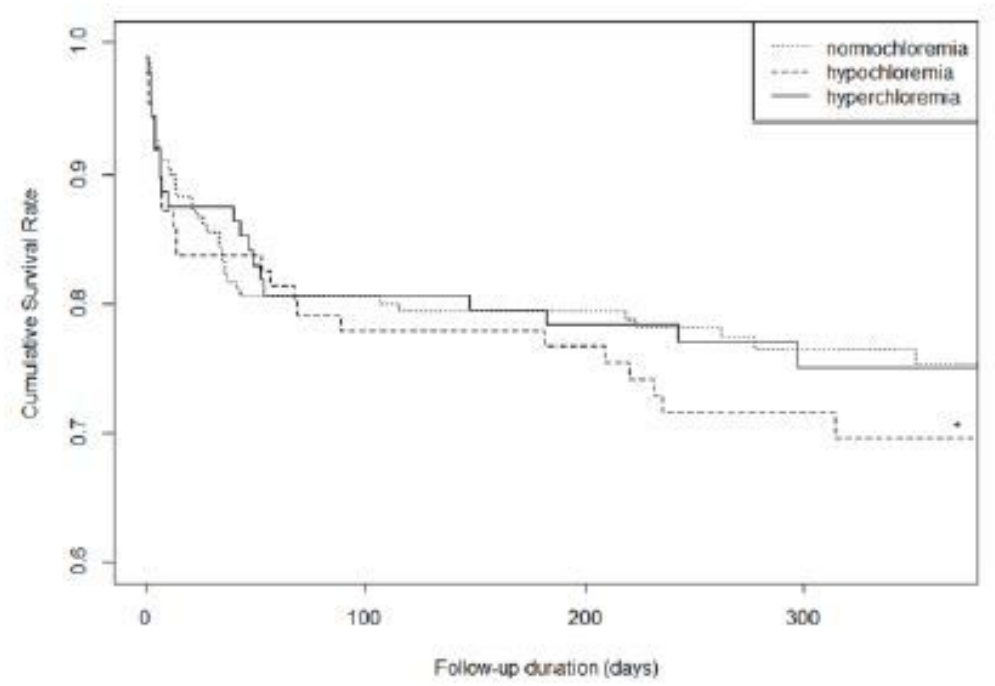

(B)

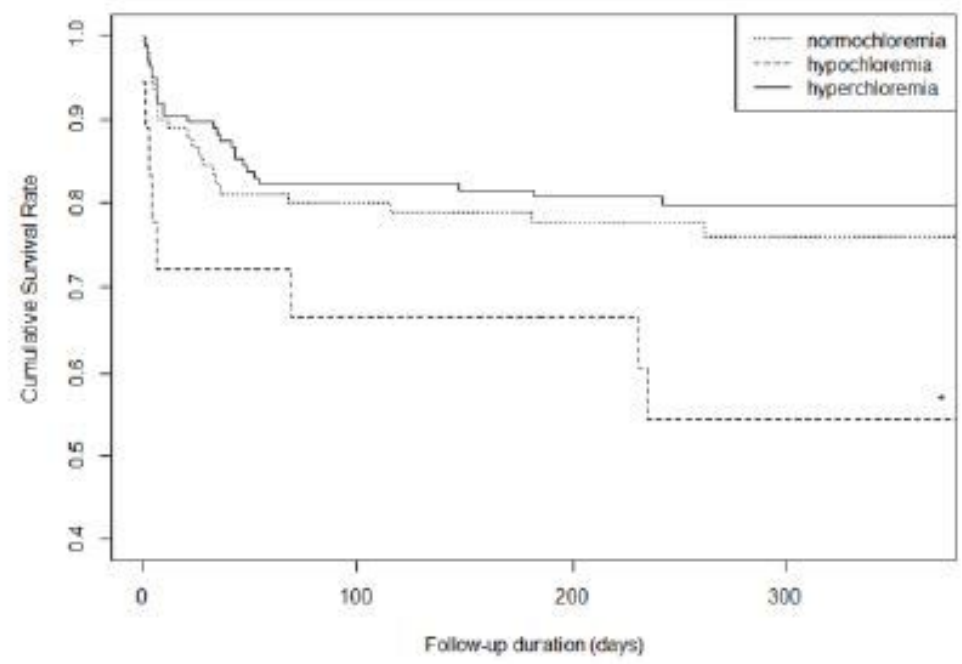

Figure 3

Kaplan Meier survival curve for (A) preoperative chloride levels and (B) postoperative chloride levels and day-30 mortality in patients undergoing emergency abdominal surgery for either intestinal obstruction or perforated viscus. Hypochloremic patients had reduced survival as compared with the normo- and hyperchloremic patients $(* p<0.05)$

\section{Supplementary Files}

This is a list of supplementary files associated with this preprint. Click to download.

- Appendix1.docx 